This item was submitted to Loughborough's Institutional Repository by the author and is made available under the following Creative Commons Licence conditions.

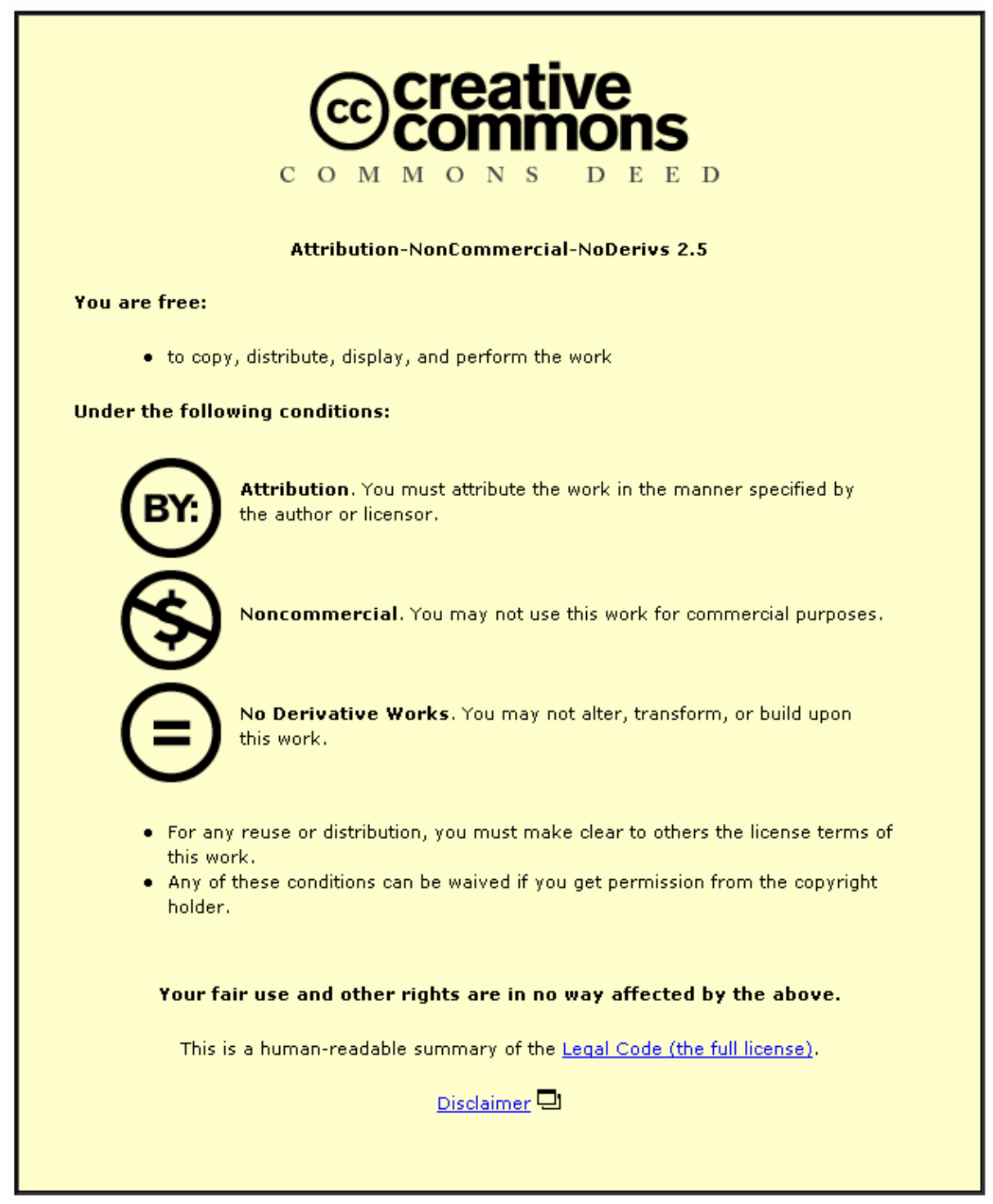

For the full text of this licence, please go to: http://creativecommons.org/licenses/by-nc-nd/2.5/ 


\title{
Particle-in-cell Monte Carlo and fluid simulations of argon-oxygen plasma: Comparisons with experiments and validations ${ }^{a)}$
}

\author{
S. H. Lee, F. Iza, and J. K. Lee ${ }^{\text {b) }}$ \\ Department of Electronics and Electrical Engineering, Pohang University of Science and Technology, \\ Pohang 790-784, Korea
}

(Received 22 November 2005; accepted 5 January 2006; published online 11 May 2006)

\begin{abstract}
Particle-in-cell Monte Carlo collision (PIC-MCC) and fluid simulations of argon-oxygen plasmas in capacitively and inductively coupled plasma reactors are presented. Potential profiles and electron/ ion kinetic information such as electron/ion energy distributions and temperatures are compared with experimental data as well as with other analytical and numerical results. One-dimensional PIC-MCC simulations compare favorably with experimental data obtained in capacitively coupled reactors over a wide range of pressure and power. Two-dimensional fluid simulations of capacitive discharges differs from the results of PIC-MCC simulations as nonlocal effects play an important role in these discharges. Fluid simulations as nonlocal inductively coupled plasmas, however, agree favorably with experimental observations. (C) 2006 American Institute of Physics.
\end{abstract}

[DOI: $10.1063 / 1.2179430]$

\section{INTRODUCTION}

As the technology of plasma processing develops, there is an increased demand for high density plasmas with good uniformity and independent control of ion flux and ionbombarding energy. Inductively coupled and capacitively coupled plasma sources are typically used for etching, deposition, and surface treatment in semiconductor manufacturing. ${ }^{1,2}$ These sources are expected to continue to play the key role in the next generation of plasma reactors. Electronegative gases such as $\mathrm{CF}_{4}, \mathrm{SF}_{6}, \mathrm{Cl}_{2}$, and $\mathrm{O}_{2}$ are typically used in etching and deposition processes. ${ }^{3}$ The analytical treatment of these discharges is not trivial and computer simulations can provided valuable information for understanding these discharges.

Particle-in-cell, fluid, and hybrid models are the numerical simulation techniques commonly used for simulating low-temperature plasmas. ${ }^{4-9}$ These simulation models have been recently advanced from qualitative analysis tools to design tools as their reliability has improved by favorable comparisons of simulation results and experimental data. ${ }^{410-12}$ In this work one-dimensional particle-in-cell Monte Carlo collision (PIC-MCC) and two-dimensional fluid models have been used. The fluid model is computationally less intensive than the PIC-MCC approach but it fails to capture nonlocal effects that are important in low pressure capacitive discharges. Due to the drift-diffusion approximation and the limitation in capturing nonlocal effects, the fluid modeling is expected to fail at pressures below $100 \mathrm{mTorr}$ and in regions of large field gradients. ${ }^{12}$ On the other hand, the PIC-MCC model is an accurate scheme for modeling the motion of charged particles but it is computationally intensive.

We present simulation results for four reactors and for each reactor a comparison between simulation results and

\footnotetext{
${ }^{\mathrm{a})}$ Paper GI2b 4, Bull. Am. Phys. Soc. 50, 138 (2005).

${ }^{\mathrm{b})}$ Invited speaker. Electronic mail: jkl@ postech.ac.kr
}

experimental data are carried out. Section II describes the simulation conditions for each reactor and Sec. III discusses the simulation results and its comparison with experimental data.

\section{SIMULATION CONDITIONS}

We carried out simulations of argon-oxygen mixture plasmas in different reactors under the same conditions as in experiments reported in the literature. Figure 1 shows the schematic of the capacitively coupled plasma (CCP) and inductively coupled plasma (ICP) sources used in the simulations. Figure 1(a) corresponds to a one-dimensional PIC-MCC simulation in a symmetrical current-driven capacitively coupled discharge. Simulations for this reactor are compared with experimental data published by Berezhnoj et $a l^{13}$ and the effect of total pressure and driving current is analyzed. Figure 1(b) corresponds to a 1D PIC-MCC simulation in an asymmetric cylindrical voltage-driven capacitively coupled discharge. Simulations for this reactor are compared with the experimental data obtained by Katsch et al. ${ }^{14}$ Here, the effects of gas composition and driving voltage are shown. Figure 1(c) corresponds to the twodimensional model used for the fluid simulations of the reactor used by Kiehlbauch et al. in Ref. 15 .

The operating conditions in Fig. 1(a) were pressures of $42-210 \mathrm{mTorr}$, currents of $0.31-0.35 \mathrm{~mA} / \mathrm{cm}^{2}$, and frequency of $13.56 \mathrm{MHz}$. The electrode gap and electrode diameter were set to $6 \mathrm{~cm}$ and $10 \mathrm{~cm}$, respectively. The operating conditions in Fig. 1(b) were a pressure of 103 mTorr, voltages of $75-280 \mathrm{~V}$, and frequency of $13.56 \mathrm{MHz}$. The inner diameter and outer diameter were set to $3.5 \mathrm{~cm}$ and $6 \mathrm{~cm}$, respectively. The operating conditions in Fig. 1(c) were a frequency of $13.56 \mathrm{MHz}$, input powers of $100-500 \mathrm{~W}$, and pressures of 5-30 mTorr.

The argon-oxygen reaction set considered in the PICMCC simulation is based on the paper of Babaeva et al. ${ }^{16} \mathrm{In}$ 


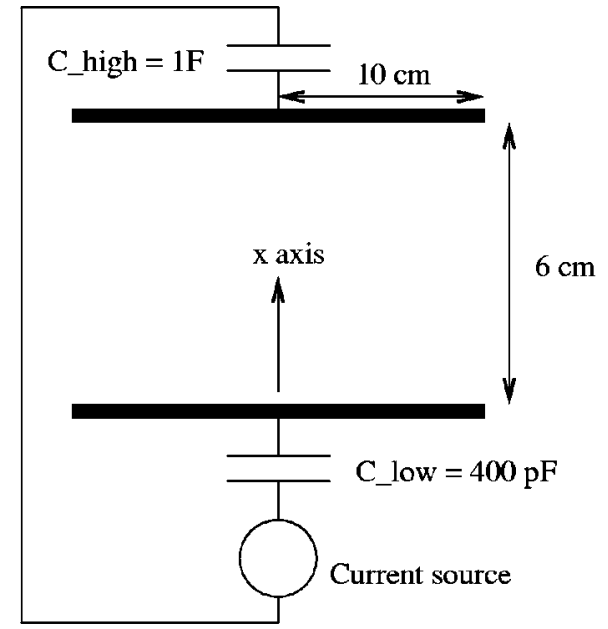

(a)

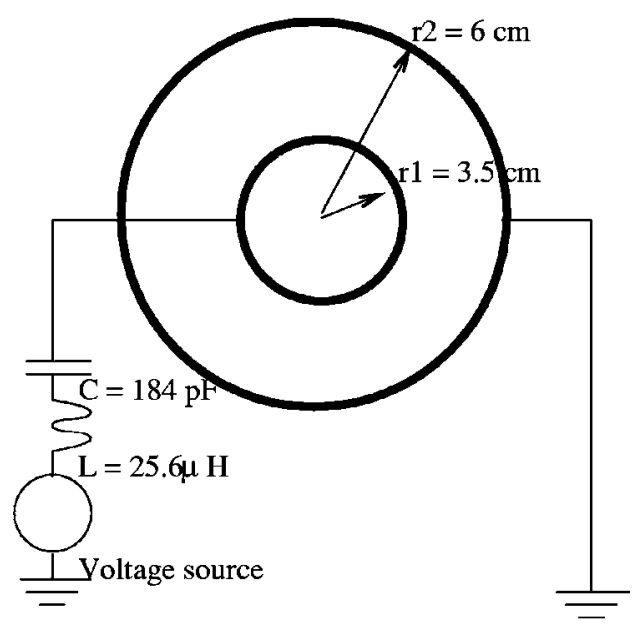

(b)

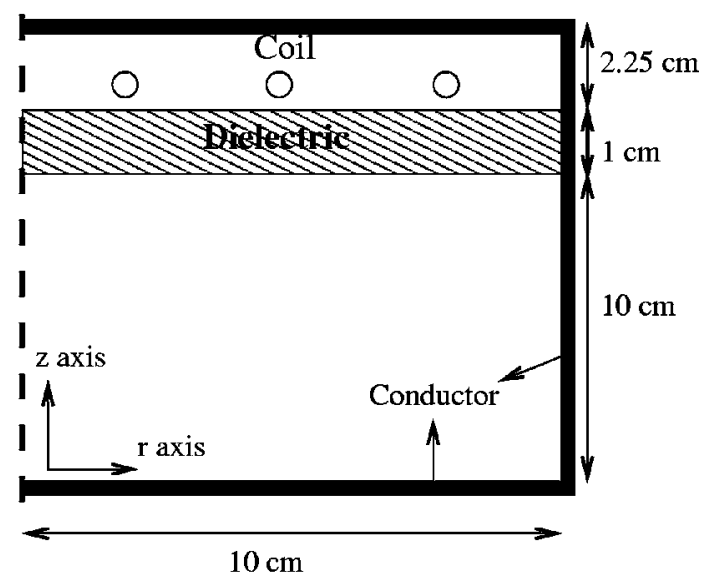

(c)

FIG. 1. Schematic diagrams of various plasma sources. (a) Symmetrical current-driven capacitively coupled discharge; (b) cylindrical voltage-driven capacitively coupled discharge; (c) planar inductively coupled discharge. Figures 1(a) and 1(b) correspond to the 1D PIC-MCC simulation and Fig. 1 (c) corresponds to the $2 \mathrm{D}$ fluid simulation.

the reaction set, we trace concentrations of only four charged species (electrons, $\mathrm{O}_{2}^{+}, \mathrm{Ar}^{+}$, and $\mathrm{O}^{-}$ions). $\mathrm{O}^{+}$is not considered in the model. The concentration of $\mathrm{O}^{+}$in CCPs is very low because the concentration of $\mathrm{O}^{+}$decreases dramatically

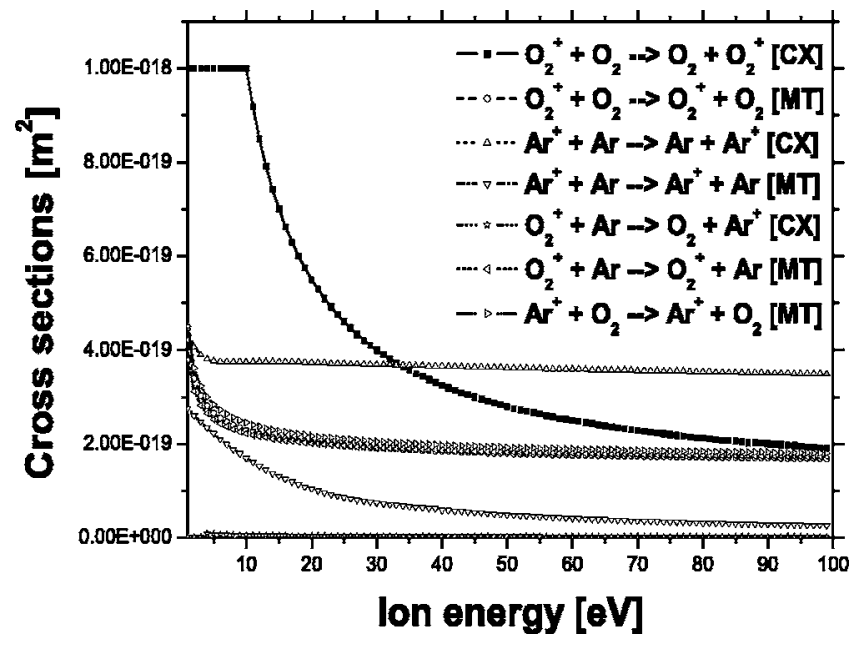

FIG. 2. Cross sections for charge exchange and momentum transfer processes of positive ions $\left(\mathrm{Ar}^{+}\right.$and $\left.\mathrm{O}_{2}^{+}\right)$.

for pressures above 10 mTorr. ${ }^{17}$ Figure 2 shows the cross sections of the charge exchange and momentum transfer processes for positive ions among the argon-oxygen reactions considered in the 1D PIC-MCC simulation. ${ }^{16}$ The cross section of charge exchange $(\mathrm{CX})$ for the positive oxygen ion $\mathrm{O}_{2}^{+}$ is the largest at energies less than $35 \mathrm{eV}$, and that of the $\mathrm{CX}$ for $\mathrm{Ar}^{+}$is the largest at energies higher than $35 \mathrm{eV}$.

Table I shows the oxygen reaction set considered in the 2D fluid simulation of pure oxygen plasma in ICPs. ${ }^{3,15,17-19}$ We consider four charged species (electrons, positive oxygen ions $\mathrm{O}_{2}^{+}$, negative oxygen ions $\mathrm{O}^{-}$, and positive oxygen ions $\left.\mathrm{O}^{+}\right)$, two metastable species $\left(\mathrm{O}_{2}^{a}\right.$ and $\left.\mathrm{O}^{D}\right)$, and background oxygen atoms and molecules $\left(\mathrm{O}\right.$ and $\left.\mathrm{O}_{2}\right)$. We assume that the background molecular oxygen density is constant and the temperature of all species except the electrons is $0.026 \mathrm{eV}$.

\section{RESULTS AND DISCUSSION}

\section{A. Comparison between 1D PIC-MCC simulations and experiments in symmetrical current-driven CCPs}

Figures 2-4 show the plasma profiles calculated by the 1D PIC-MCC simulation of a pure oxygen plasma in symmetrical current-driven capacitively coupled rf discharges. Figure 3 shows the density profiles with pressure and current densities is parabolic. The axial density profiles of $\mathrm{O}_{2}^{+}$and $\mathrm{O}^{-}$ are parabolic at a pressure of $42 \mathrm{mTorr}$ and a current of $0.219 \mathrm{~A}$, as shown in Fig. 3(a). The $\mathrm{O}_{2}^{+}$and $\mathrm{O}^{-}$densities in the bulk region decrease gradually with increasing pressure. The $\mathrm{O}^{-}$densities in the bulk region are $1.81 \times 10^{15}, 1.54$ $\times 10^{15}$, and $1.4 \times 10^{15} \mathrm{~m}^{-3}$ for 42,140 , and $210 \mathrm{mTorr}$, respectively. The $\mathrm{O}_{2}^{+}$density in the bulk region decreases from $2.07 \times 10^{15}$ to $10^{15} \mathrm{~m}^{-3}$ with increasing pressure.

Gudmundsson et al. reported that the main loss mechanism of $\mathrm{O}^{-}$changes from the recombination with $\mathrm{O}^{+}$, to the detachment by collisions with $\mathrm{O}$ and the recombination with $\mathrm{O}_{2}^{+}$with increasing pressure. ${ }^{17}$ The importance of recombination with $\mathrm{O}_{2}^{+}$increases with increasing pressure, as shown in Figs. 3(a) and 3(b). The axial distribution of $\mathrm{O}^{-}$and $\mathrm{O}_{2}^{+}$ densities with pressure agrees well with the experimental data measured by Berezhnoj et al. ${ }^{13}$ Figure 4 shows plasma 
TABLE I. Oxygen reaction set assuming a Maxwellian electron energy distribution in 2D fluid simulation of ICPs.

\begin{tabular}{|c|c|c|c|}
\hline Number/description & Reaction & Rate constant $\left(\mathrm{cm}^{3} / \mathrm{s}\right)$ & Electron energy loss $(\mathrm{eV})$ \\
\hline 1. Elastic scattering ${ }^{\mathrm{a}}$ & $e+\mathrm{O}_{2} \rightarrow \mathrm{O}_{2}+e$ & $4.7 \mathrm{e}-8 T_{e}^{a 0.5}$ & $3 T_{e}\left(m_{e} / m_{n}\right)$ \\
\hline 2. Dissociation $\mathrm{I}^{\mathrm{a}}$ & $e+\mathrm{O}_{2} \rightarrow 2 \mathrm{O}+e$ & $4.2 \mathrm{e}-9 \exp \left(-5.6 / T_{e}\right)$ & 6.4 \\
\hline 3. Disso. attachment $\mathrm{I}^{\mathrm{a}}$ & $e+\mathrm{O}_{2} \rightarrow \mathrm{O}^{-}+\mathrm{O}$ & $8.8 \mathrm{e}-11 \exp \left(-4.4 / T_{e}\right)$ & 3.637 \\
\hline 4. Ionization $\mathrm{I}^{\mathrm{a}, \mathrm{b}}$ & $e+\mathrm{O}_{2} \rightarrow \mathrm{O}_{2}^{+}+2 e$ & $9.0 \mathrm{e}-10 T_{e}^{0.5} \exp \left(-12.6 / T_{e}\right)$ & 12.6 \\
\hline 5. Detachment $\mathrm{I}^{\mathrm{a}}$ & $e+\mathrm{O}^{-} \rightarrow \mathrm{O}+2 e$ & $2.0 \mathrm{e}-7 \exp \left(-5.5 / T_{e}\right)$ & 5.5 \\
\hline 6. Recombination $\mathrm{I}^{\mathrm{a}}$ & $e+\mathrm{O}_{2}^{+} \rightarrow 2 \mathrm{O}$ & $5.2 \mathrm{e}-9 / T_{e}$ & -6.96 \\
\hline 7. Recombination $\mathrm{II}^{\mathrm{c}}$ & $\mathrm{O}^{-}+\mathrm{O}_{2}^{+} \rightarrow \mathrm{O}+\mathrm{O}_{2}$ & $1 e-7$ & \\
\hline 8. Detachment $\mathrm{II}^{\mathrm{c}}$ & $\mathrm{O}^{-}+\mathrm{O} \rightarrow \mathrm{O}_{2}+e$ & $3 e-10$ & \\
\hline 9. Recombination III $^{\mathrm{a}}$ & $\mathrm{O}^{-}+\mathrm{O}_{2}^{+} \rightarrow 3 \mathrm{O}$ & $1 e-7$ & \\
\hline 10. Disso. attachment II ${ }^{\mathrm{a}, \mathrm{b}}$ & $e+\mathrm{O}_{2} \rightarrow \mathrm{O}^{-}+\mathrm{O}^{+}+e$ & $7.1 \mathrm{e}-11 T_{e}^{0.5} \exp \left(-17 / T_{e}\right)$ & 17 \\
\hline 11. Disso. ionization ${ }^{\mathrm{a}}$ & $e+\mathrm{O}_{2} \rightarrow \mathrm{O}+\mathrm{O}^{+}+2 e$ & $5.3 \mathrm{e}-10 T_{e}^{0.9} \exp \left(-20 / T_{e}\right)$ & 20 \\
\hline 12. Ionization $\mathrm{II}^{\mathrm{a}}$ & $e+\mathrm{O} \rightarrow \mathrm{O}^{+}+2 e$ & $9.0 \mathrm{e}-9 T_{e}^{0.7} \exp \left(-13 / T_{e}\right)$ & 13 \\
\hline 13. Recombination IV ${ }^{\mathrm{a}}$ & $\mathrm{O}^{-}+\mathrm{O}^{+} \rightarrow 2 \mathrm{O}$ & $2.7 \mathrm{e}-7\left(300 / T_{n}\right)^{0.5 \mathrm{~g}}$ & \\
\hline 14. Charge exchange ${ }^{a}$ & $\mathrm{O}^{-}+\mathrm{O}_{2} \rightarrow \mathrm{O}_{2}+\mathrm{O}^{-}$ & $2 \mathrm{e}-11\left(300 / T_{n}\right)^{0.5}$ & \\
\hline 15. Electronic excitation $\mathrm{I}^{\mathrm{a}, \mathrm{b}}$ & $e+\mathrm{O}_{2} \rightarrow \mathrm{O}_{2}+e^{\mathrm{f}}$ & $1.7 \mathrm{e}-9 \exp \left(-3.1 / T_{e}\right)$ & 0.98 \\
\hline 16. Metastable quenching $\mathrm{I}^{\mathrm{a}}$ & $e+\mathrm{O}_{2} \rightarrow \mathrm{O}_{2}+e^{\mathrm{f}}$ & $5.6 \mathrm{e}-9 \exp \left(-2.2 / T_{e}\right)$ & -0.98 \\
\hline 17. Metastable quenching $\mathrm{II}^{\mathrm{a}}$ & $\mathrm{O}_{2}+\mathrm{O}_{2} \rightarrow 2 \mathrm{O}_{2}{ }^{\mathrm{f}}$ & $2.2 \mathrm{e}-18\left(T_{n} / 300\right)^{0.8}$ & \\
\hline 18. Metastable quenching III $^{\mathrm{d}}$ & $\mathrm{O}_{2}+\mathrm{O} \rightarrow \mathrm{O}_{2}+\mathrm{O}^{\mathrm{f}}$ & $2 e-16$ & \\
\hline 19. Dissociation $\mathrm{II}^{\mathrm{a}}$ & $e+\mathrm{O}_{2} \rightarrow \mathrm{O}+\mathrm{O}^{D}+e$ & $5 e-8 \exp \left(-8.4 / T_{e}\right)$ & 8.57 \\
\hline 20. Disso. attachment III ${ }^{\mathrm{b}, \mathrm{e}}$ & $e+\mathrm{O}_{2} \rightarrow \mathrm{O}^{-}+\mathrm{O}^{\mathrm{f}}$ & $2.28 \mathrm{e}-10 \exp \left(-2.29 / T_{e}\right)$ & \\
\hline 21. Metastable quenching $\mathrm{IV}^{\mathrm{a}}$ & $e+\mathrm{O}^{D} \rightarrow e+\mathrm{O}$ & $8 e-9$ & -1.97 \\
\hline 22. Ionization $\mathrm{III}^{\mathrm{a}}$ & $e+\mathrm{O}^{D} \rightarrow \mathrm{O}^{+}+2 e$ & $9.0 \mathrm{e}-9 T_{e}^{0.7} \exp \left(-11.6 / T_{e}\right)$ & 11.6 \\
\hline 23. Metastable quenching $\mathrm{V}^{\mathrm{a}}$ & $\mathrm{O}^{D}+\mathrm{O} \rightarrow 2 \mathrm{O}$ & $8 e-12$ & \\
\hline 24. Metastable quenching $\mathrm{VI}^{\mathrm{a}}$ & $\mathrm{O}^{D}+\mathrm{O}_{2} \rightarrow \mathrm{O}+\mathrm{O}_{2}$ & $7 \mathrm{e}-12 \exp \left(67 / T_{n}\right)$ & \\
\hline 25. Metastable quenching VII ${ }^{\mathrm{a}}$ & $\mathrm{O}^{D}+\mathrm{O}_{2} \rightarrow \mathrm{O}+\mathrm{O}_{2}{ }^{\mathrm{f}}$ & $1 e-12$ & \\
\hline 26. Ionization $\mathrm{IV}^{\mathrm{b}, \mathrm{e}}$ & $e+\mathrm{O}_{2} \rightarrow \mathrm{O}_{2}^{+}+2 e^{\mathrm{f}}$ & $9.0 \mathrm{e}-10 T_{e}^{2} \exp \left(-11.6 / T_{e}\right)$ & 11.08 \\
\hline 27. Electronic excitation II $^{\mathrm{a}}$ & $e+\mathrm{O} \rightarrow \mathrm{O}^{D}+2 e$ & $4.2 \mathrm{e}-9 \exp \left(-2.25 / T_{e}\right)$ & 1.97 \\
\hline 28. Dissociation III ${ }^{\mathrm{b}, \mathrm{e}}$ & $e+\mathrm{O}_{2} \rightarrow 2 \mathrm{O}+e^{\mathrm{f}}$ & $4.2 \mathrm{e}-9 \exp \left(-4.6 / T_{e}\right)$ & 5.42 \\
\hline
\end{tabular}

${ }^{\mathrm{a}}$ Reference 3 .

${ }^{\mathrm{b}}$ Reference 17.

${ }^{\mathrm{c}}$ Reference 18 .

${ }^{\mathrm{d}}$ Reference 19.

${ }^{\mathrm{e}}$ Reference 15

${ }^{\mathrm{f}} T_{e}$ is the electron temperature in $\mathrm{eV}$.

${ }^{\mathrm{g}} T_{n}$ is the neutral gas temperature in $\mathrm{K}$.

characteristics such as the plasma potential, electron temperature, and electron energy probability function (EEPF) in the bulk region. As the pressure increases, the electron temperature and the sheath length decrease but the plasma potential increases. The EEPF, which is calculated in the bulk region, does not change from bi-Maxwellian-type with increasing pressure.

\section{B. Comparison between 1D PIC-MCC simulations and experiments in cylindrical voltage-driven CCPs}

Figures 5 and 6 show the charged species density, plasma potential, and ratio of oxygen negative ion density to plasma density, which is the sum of the electron and $\mathrm{O}^{-}$ densities. We observed plasma characteristics with increasing voltage. Figure 5 shows the radial distribution of charged species with voltage. The electron density is lower than the $\mathrm{O}^{-}$density and the radial profiles of the electron and $\mathrm{O}^{-}$ densities are flat at 75 and $150 \mathrm{~V}$, as shown in Figs. 5(a) and 5 (b). The electron density exceeds the $\mathrm{O}^{-}$density at $280 \mathrm{~V}$.
The ratio of negative oxygen density to plasma density decreases from 0.78 to 0.38 with increasing voltage. As shown in Fig. 6(b), the plasma potential increases with increasing voltage and the sheath length also increases because of the confinement of $\mathrm{O}^{-}$by the increased plasma potential. The radial distribution of electron and $\mathrm{O}^{-}$, and the $\mathrm{O}^{-} / \mathrm{O}_{2}^{+}$density ratio calculated by the 1D PIC-MCC simulation are consistent with the experimental data of Katsch et al. ${ }^{14}$

Figure 7 shows the charged species density, potential, and electron temperature with the ratio of $\mathrm{Ar}$ to $\mathrm{O}_{2}$ at $115 \mathrm{mTorr}$ and $160 \mathrm{~V}$. As the ratio increases, the concentration of electrons and $\mathrm{Ar}^{+}$increases due to the increase of background argon atoms Ar but the concentration of $\mathrm{O}^{-}$and $\mathrm{O}_{2}^{+}$decreases because of the decrease of background oxygen molecules $\mathrm{O}_{2}$. This trend of electron and $\mathrm{O}^{-}$densities with the $\mathrm{Ar} / \mathrm{O}_{2}$ ratio is consistent with the experimental data. ${ }^{14}$ The plasma densities, which are the sum of $\mathrm{Ar}^{+}$and $\mathrm{O}_{2}^{+}$densities, are $1.61 \times 10^{15}, 1.85 \times 10^{15}, 2.09 \times 10^{15}, 2.75 \times 10^{15}$, and $3.93 \times 10^{15} \mathrm{~m}^{-3}$ for $\mathrm{Ar} /\left(\mathrm{Ar}+\mathrm{O}_{2}\right)$ ratios of $0.01,0.3,0.5$, 


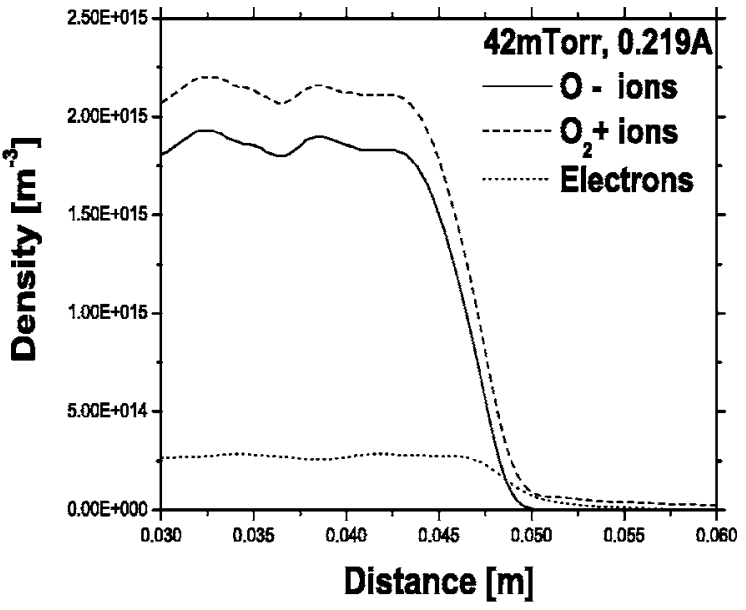

(a)

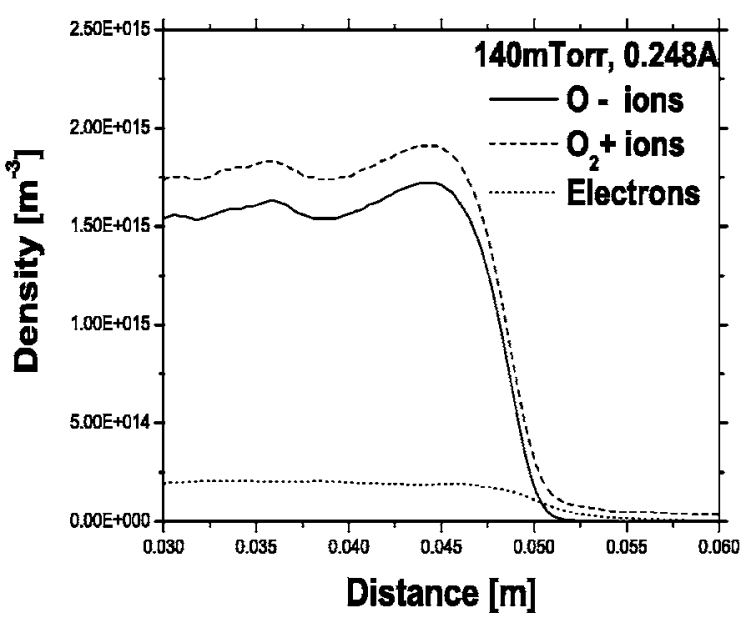

(b)

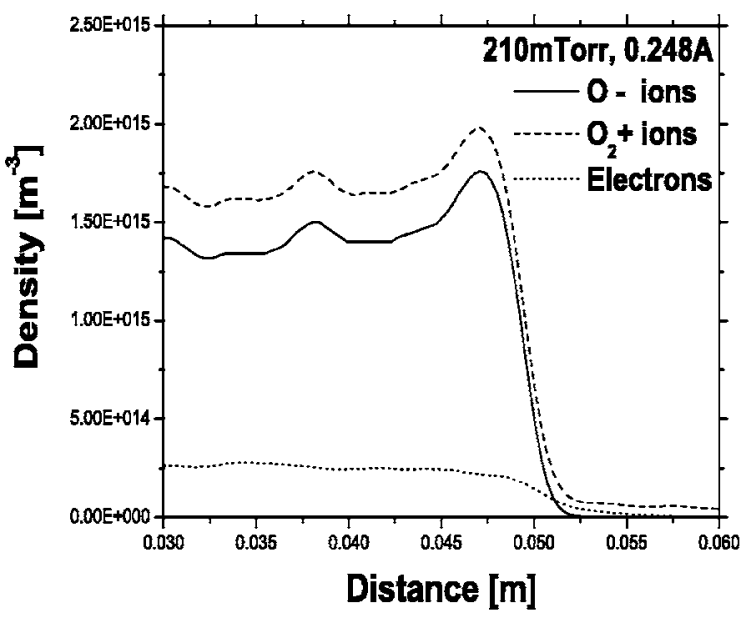

(c)

FIG. 3. Density profiles between $x=0.03 \mathrm{~m}$ and $x=0.06 \mathrm{~m}$ with pressure at currents of 0.219 and $0.248 \mathrm{~A}$ in symmetrical current-driven capacitively coupled rf discharges.

0.7 , and 0.99 , respectively. In oxygen gas, the collisional energy loss per electron-ion pair created can be 2-3 times higher than for argon gas at same electron temperature below $10 \mathrm{eV}$, resulting in the lower plasma density. ${ }^{3,20}$

Takechi et $a .^{20}$ reported that the plasma density increases with increasing Ar fraction. In an inductively coupled

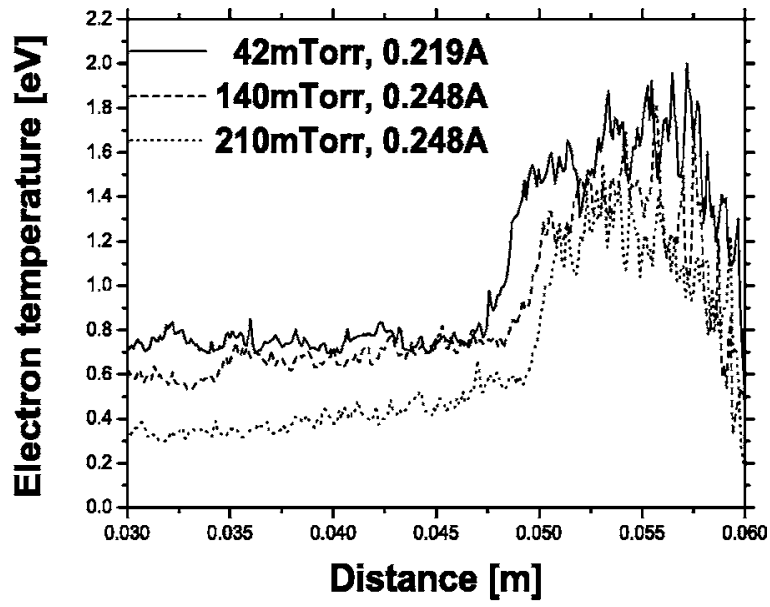

(a)

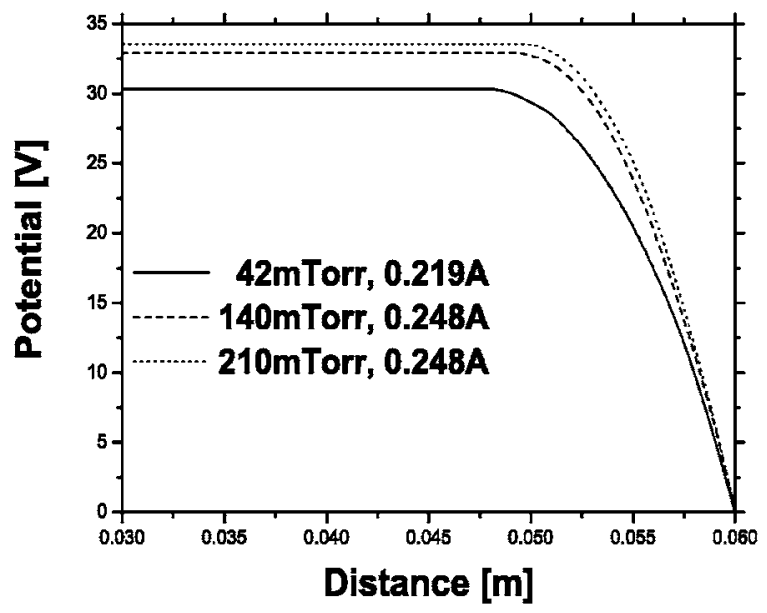

(b)

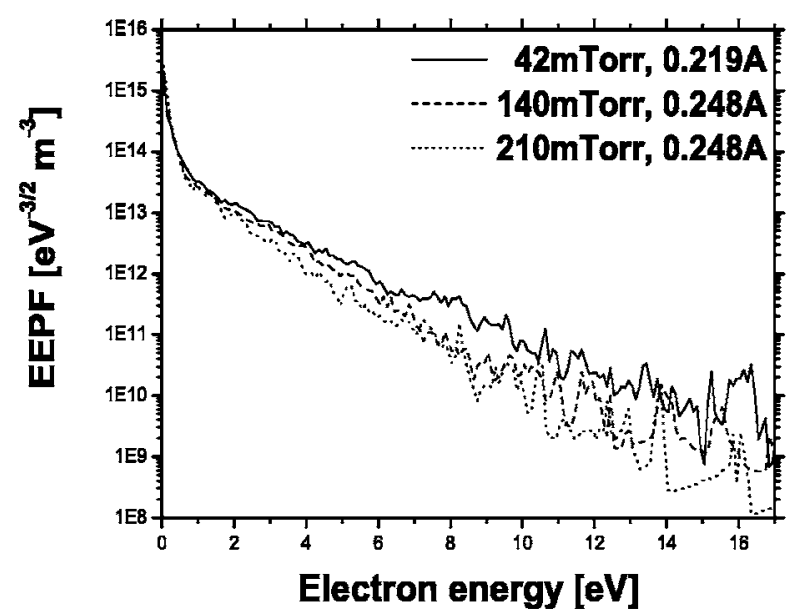

(c)

FIG. 4. Plasma profiles with pressure at currents of 0.219 and 0.248 A for pure oxygen plasma in symmetrical current-driven capacitively coupled rf discharges. (a) Electron temperature between $x=0.03 \mathrm{~m}$ and $x=0.06 \mathrm{~m}$; (b) potential between $x=0.03 \mathrm{~m}$ and $x=0.06 \mathrm{~m}$; (c) electron energy probability function in the bulk of discharge.

large area plasma source, and the addition of 50\% $\mathrm{Ar}$ increases the plasma density by a factor of 2 . The plasma density calculated by the 1D PIC-MCC simulation of a cylindrical voltage-driven capacitively coupled rf discharges also 


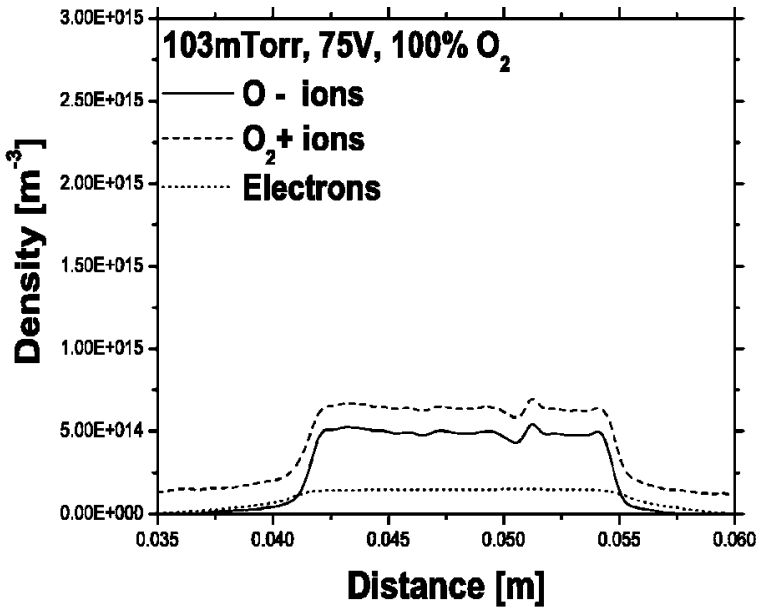

(a)

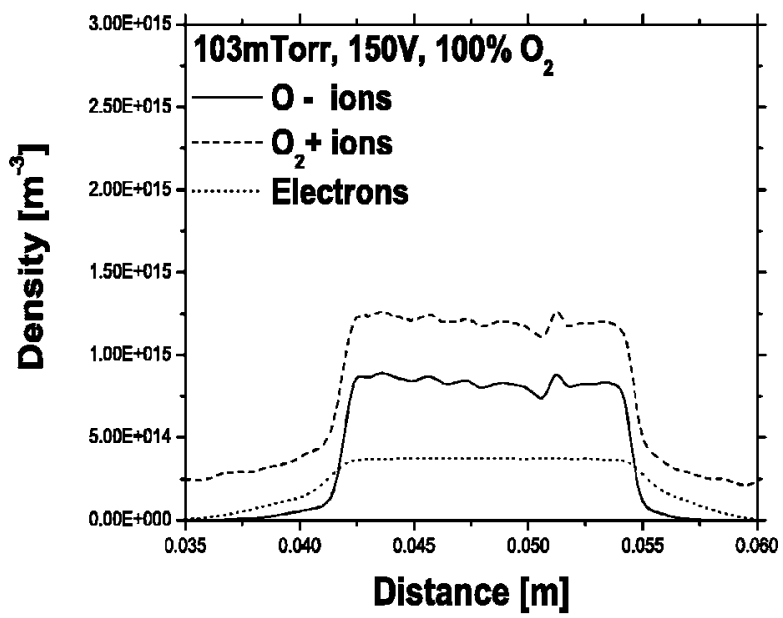

(b)

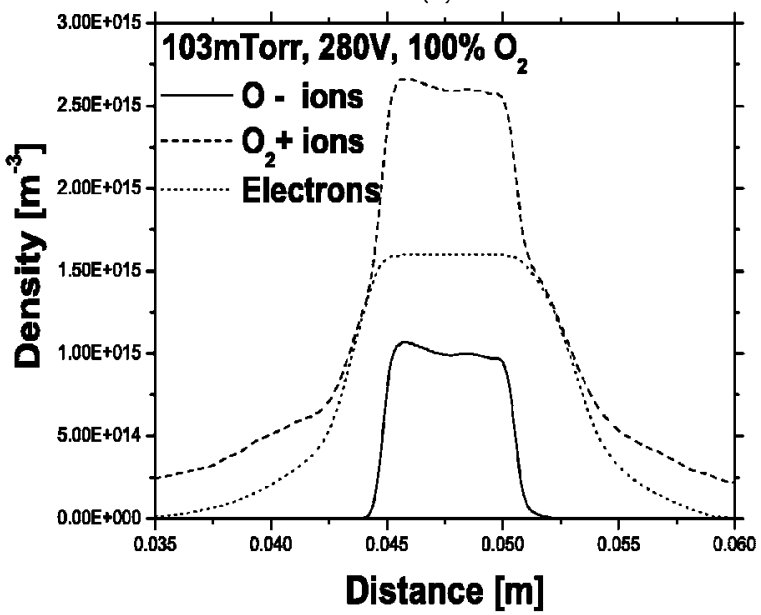

(c)

FIG. 5. Density profiles with voltage at 103 mTorr in cylindrical voltagedriven capacitively coupled rf discharges.

increases with increasing the $\mathrm{Ar} / \mathrm{O}_{2}$ ratio. The addition of $50 \%$ Ar increases the plasma density by a factor of 1.3 and the addition of $70 \% \mathrm{Ar}$ increases the plasma density by a factor of 1.7. The electron temperature decreases with increasing the $\mathrm{Ar} / \mathrm{O}_{2}$ ratio. The plasma potential decreases from $60 \mathrm{~V}$ to $48 \mathrm{~V}$ with increasing $\mathrm{Ar} / \mathrm{O}_{2}$ ratio, but does not change much for ratios less than 0.7 .

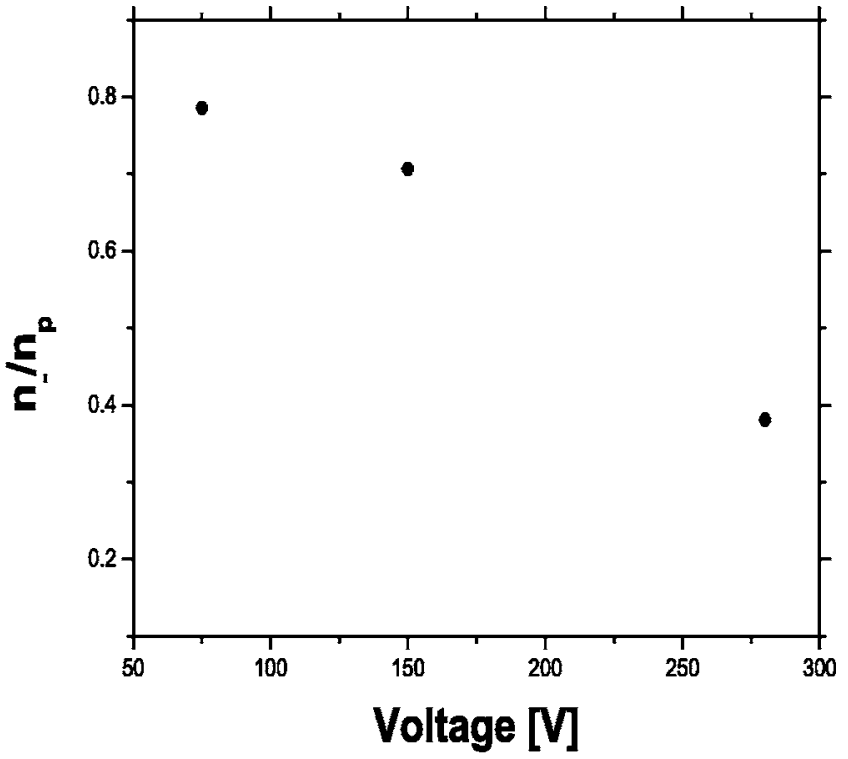

(a)

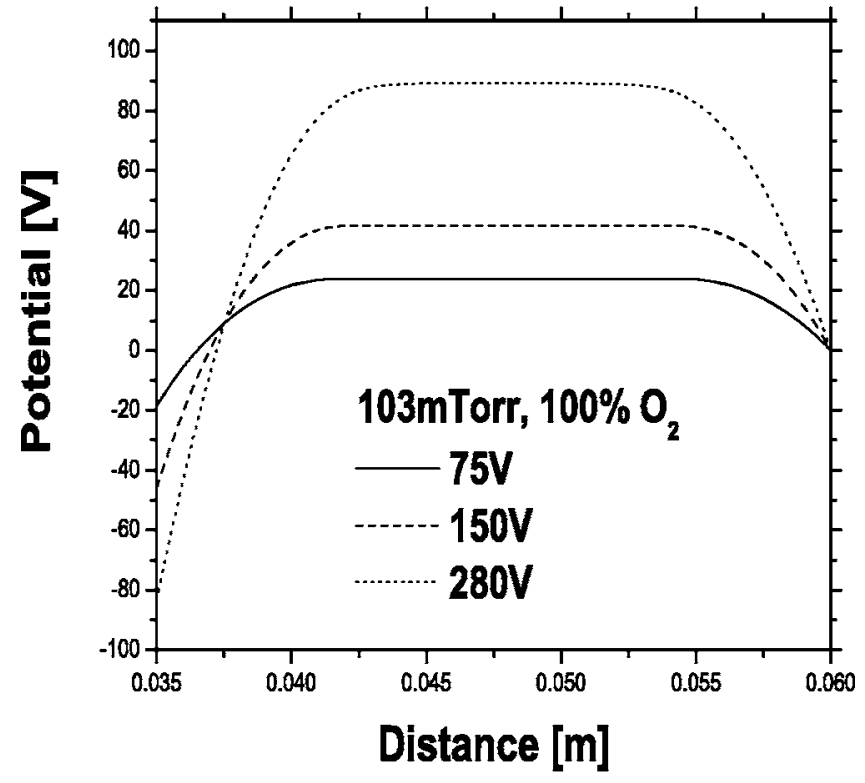

(b)

FIG. 6. Plasma profiles with voltage at pressure of 103 mTorr in cylindrical voltage-driven capacitively coupled rf discharges. (a) Ratio of negative oxygen density to plasma density; (b) plasma potential.

Figure 8 shows the ion energy distribution function (IEDF) of $\mathrm{O}_{2}^{+}$with the $\mathrm{Ar} / \mathrm{O}_{2}$ ratio. The IEDF is normalized to the total ion number per unit area. At low pressure, the IEDF of positive ions at the electrode is affected by the rf frequency, the sheath length, and the mean potential drop between the driven electrode and the plasma. ${ }^{21}$ At high pressure, the charge exchange $(\mathrm{CX})$ and momentum transfer (MT) processes also play an important role in the IEDF. ${ }^{16} \mathrm{We}$ carried out simulations for three cases to observe the dominant process for determining the IEDF. The first case considered both CX and MT processes in Fig. 2, the second case only the MT process, and the last case only the CX process. As the $\mathrm{Ar} / \mathrm{O}_{2}$ ratio increases, the dominant process for the IEDF of $\mathrm{O}_{2}^{+}$also changes from the $\mathrm{CX}$ to the MT process. 


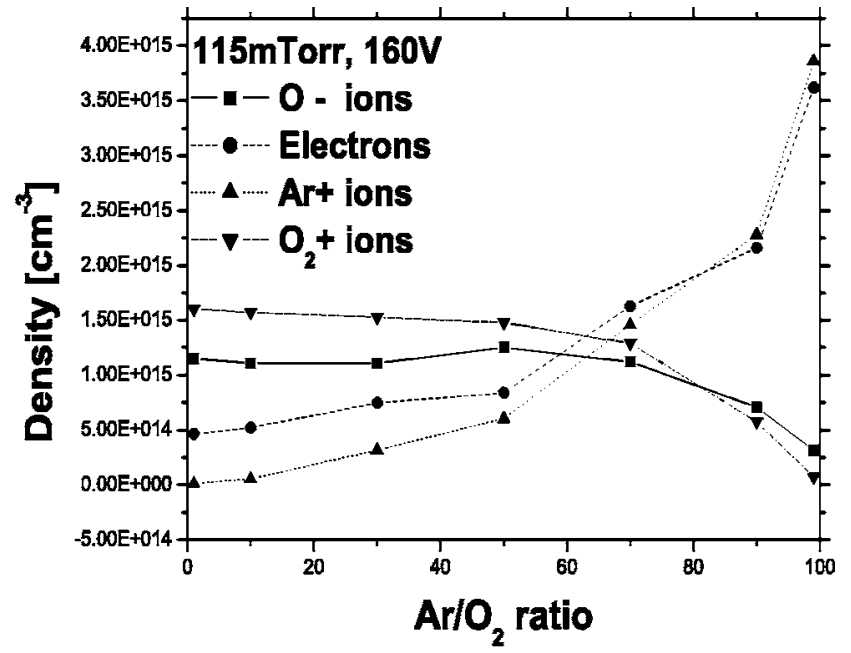

(a)

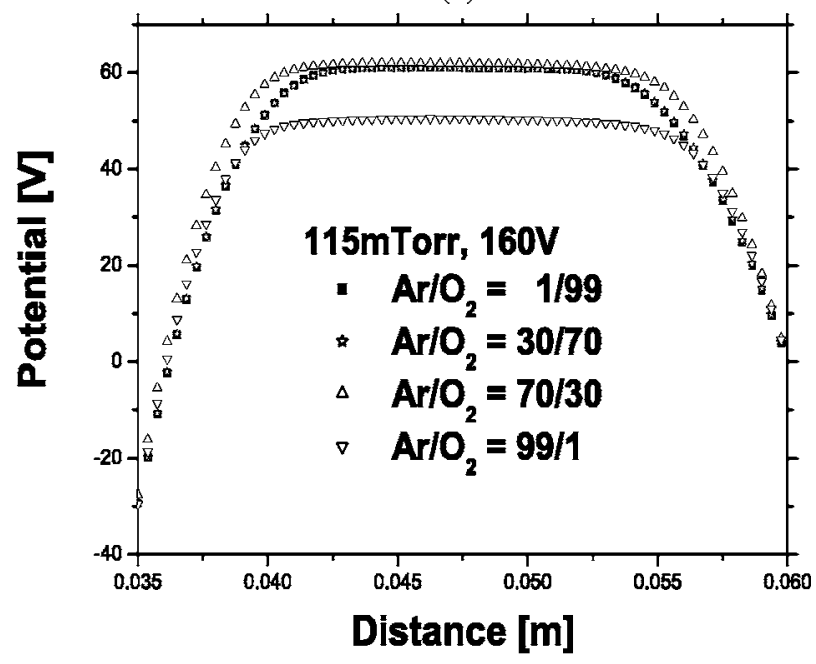

(b)

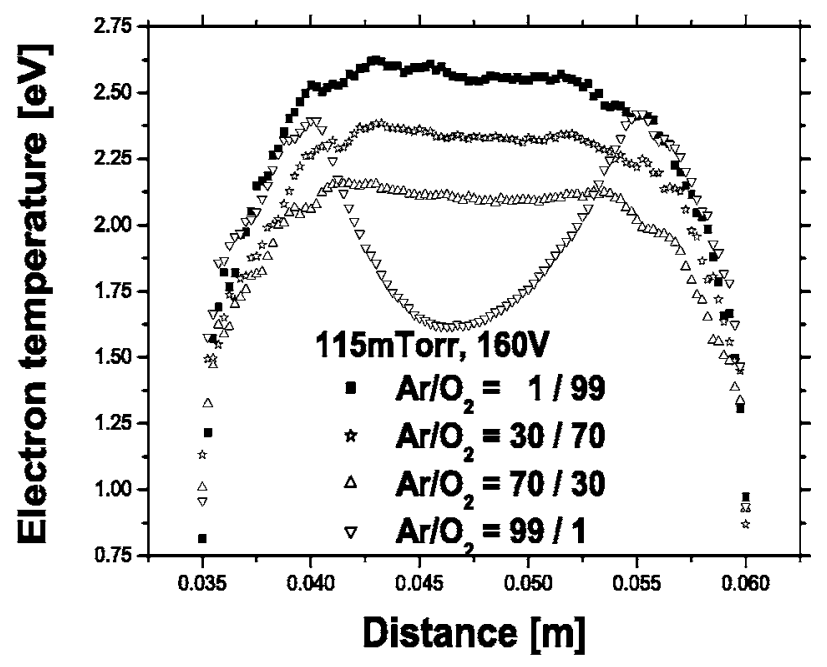

(c)

FIG. 7. Plasma profiles with varying $\mathrm{Ar} / \mathrm{O}_{2}$ ratios. (a) Charged species density; (b) potential; (c) electron temperature.

For the 10:90 $\mathrm{Ar} / \mathrm{O}_{2}$ ratio, the IEDF of $\mathrm{O}_{2}^{+}$considering both $\mathrm{CX}$ and MT processes is similar to the one considering only the CX process. For the 90:10 $\mathrm{Ar} / \mathrm{O}_{2}$ ratio, the IEDF of $\mathrm{O}_{2}^{+}$ considering both $\mathrm{CX}$ and MT processes is similar to the one considering only the MT process.

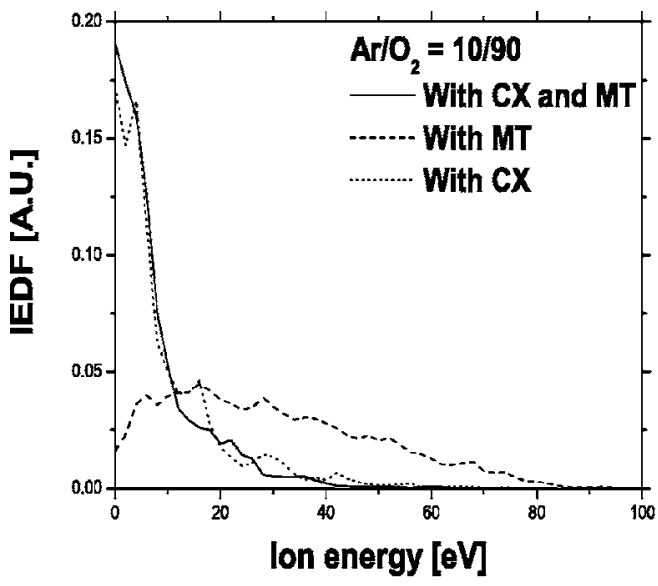

(a)

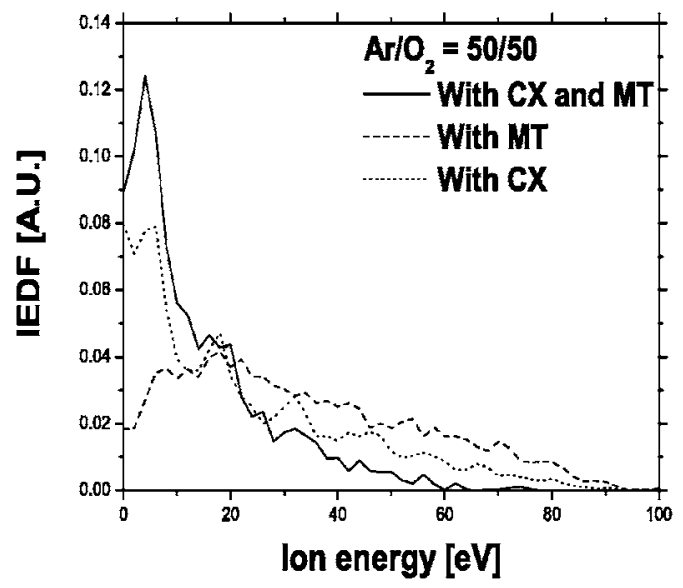

(b)

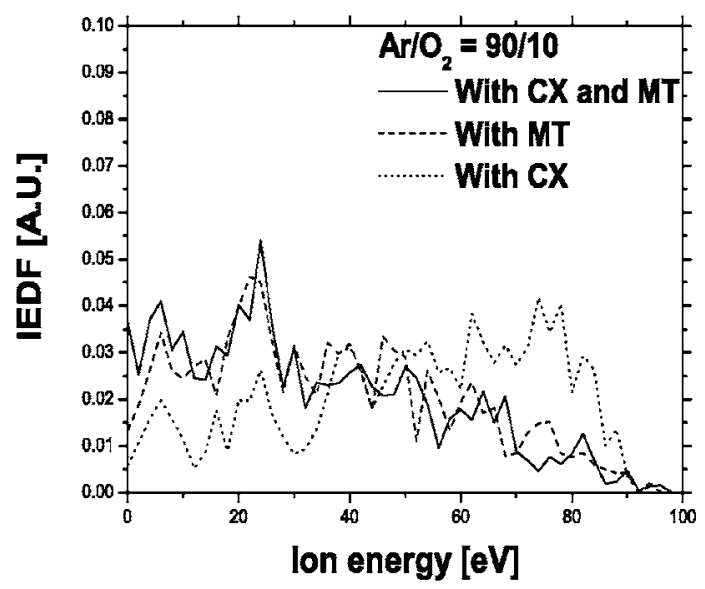

(c)

FIG. 8. IEDFs at the electrode of positive ion $\mathrm{O}_{2}^{+}$with varying $\mathrm{Ar} / \mathrm{O}_{2}$ ratios.

C. Comparison between 1D PIC-MCC and 2D fluid simulations in cylindrical voltage-driven CCPs

Figure 9 shows the plasma profiles calculated by $1 \mathrm{D}$ PIC-MCC and 2D fluid simulations of oxygen plasma in a cylindrical voltage-driven capacitively coupled discharge. The operating conditions were $13.56 \mathrm{MHz}, 150 \mathrm{~V}$, and 103 mTorr. The density profiles calculated by the 1D PIC-MCC simulation are similar to experimental data, but the density profiles calculated by the 2D fluid simulation 


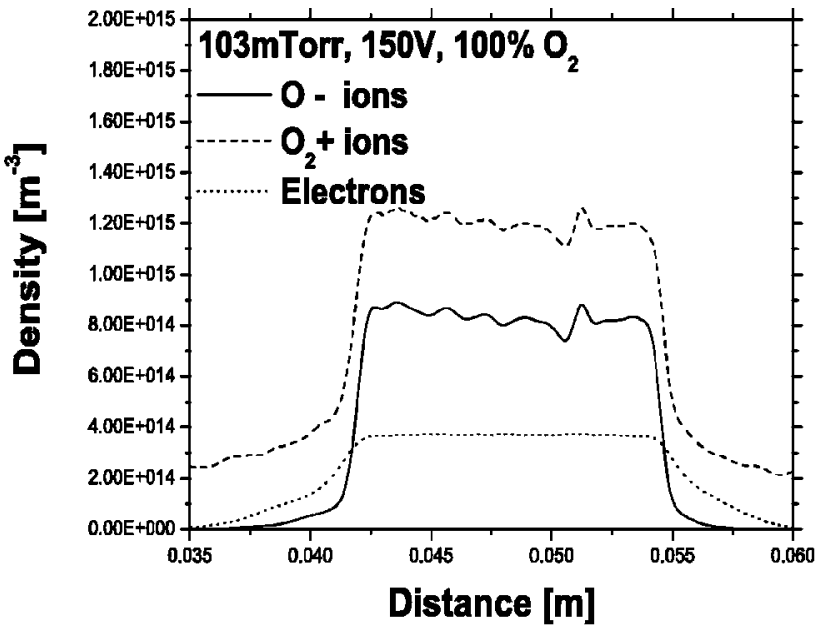

(a)

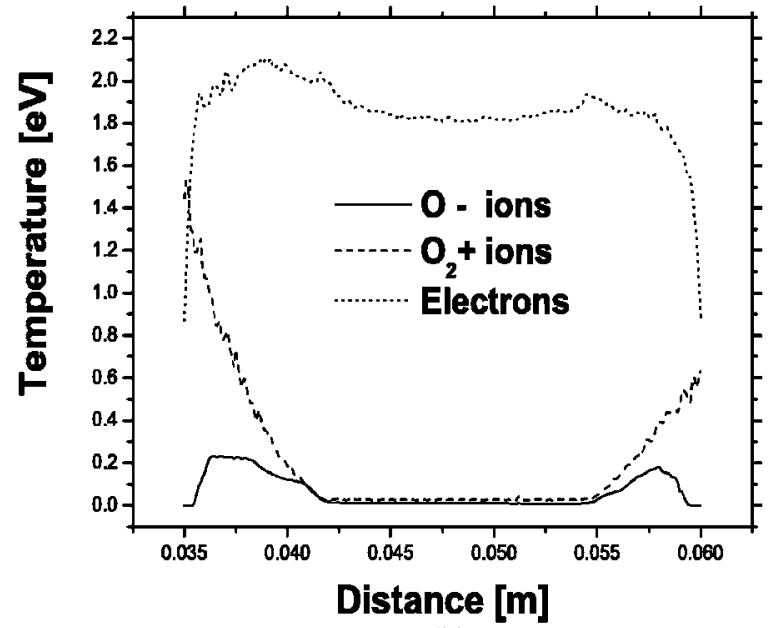

(b)

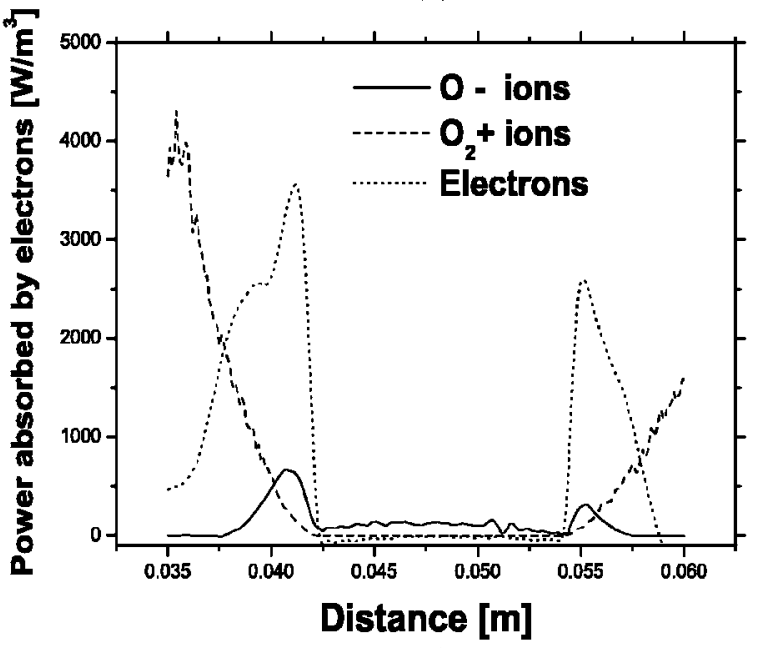

(c)

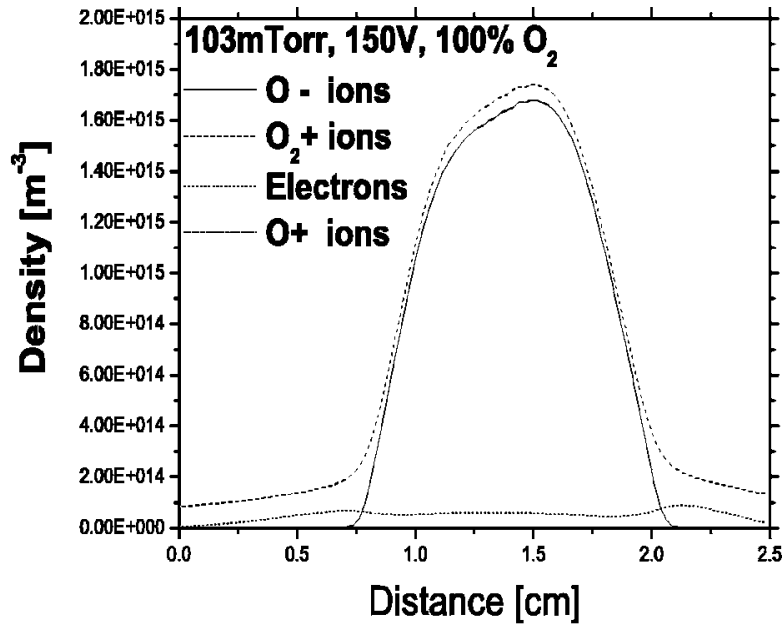

(d)

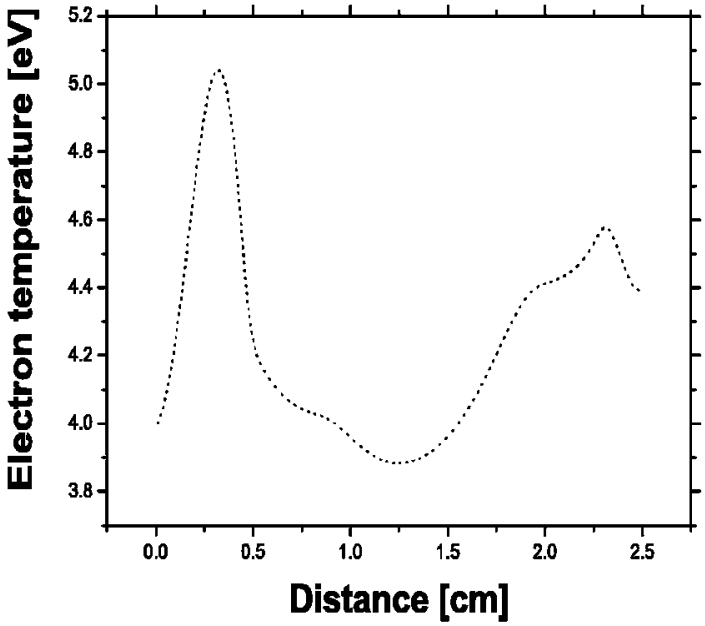

(e)

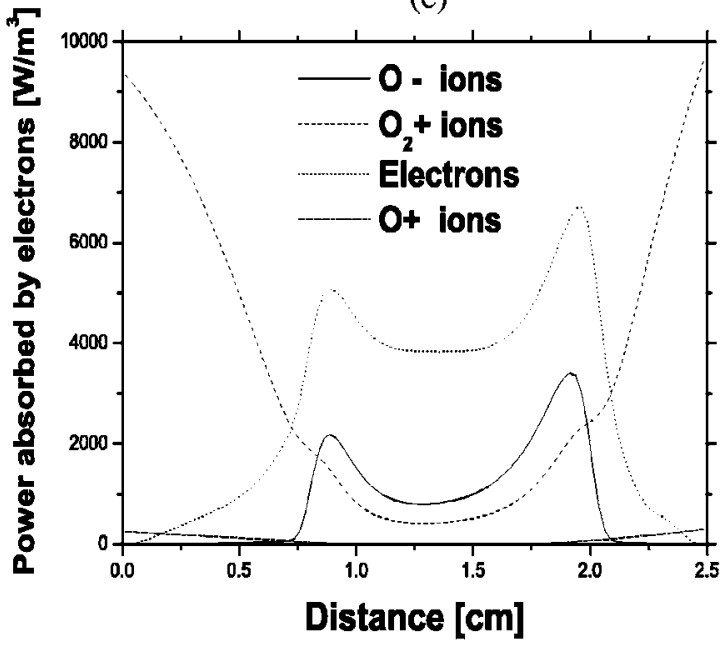

(f)

FIG. 9. Comparisons of 1D PIC-MCC simulation (a-c) and 2D fluid simulation (d-f) data. (a) and (d) Density profiles; (b) and (e) temperature profiles; (c) and (f) profiles of power absorbed by electrons. The temperature of all ion species was assumed to be $0.026 \mathrm{eV}$ in the fluid simulation.

differ considerably and are similar to the relaxation continuum simulation data of Shibata et $a .^{22,23}$ The electron temperature and power absorbed by electrons calculated by the 2D fluid simulation differ from 1D PIC-MCC simulation data. These data show that fluid simulations cannot describe the kinetic effects of charged particles, which are critical in CCPs.

\section{Comparison between 2D fluid simulations and experiments in ICPs}

We simulated an oxygen plasma in an inductively coupled plasma source, as shown in Fig. 1(c). The operating conditions were a frequency of $13.56 \mathrm{MHz}$, input powers of $100-500 \mathrm{~W}$, and pressures of 5-30 mTorr. Figure 10 shows 


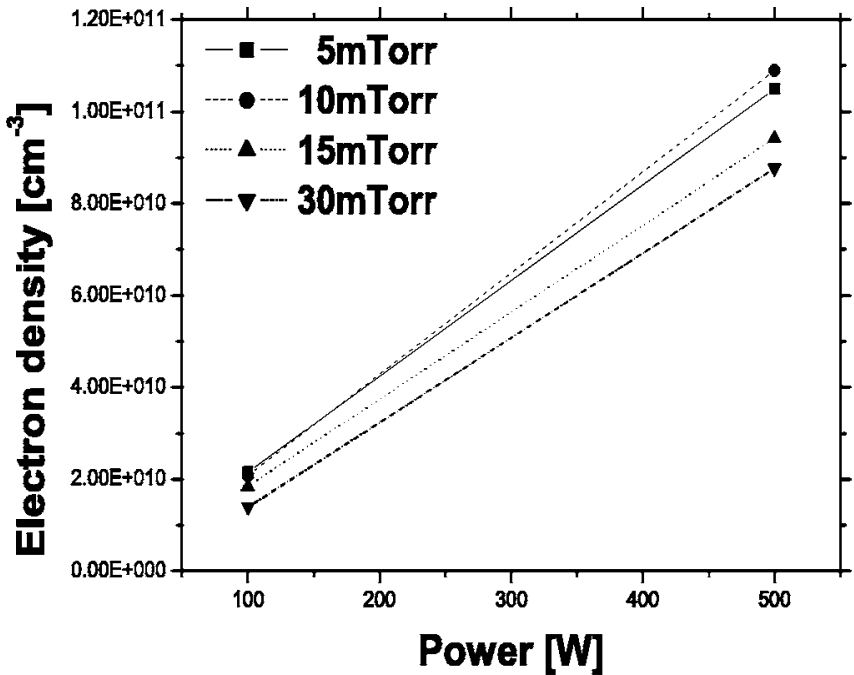

(a)

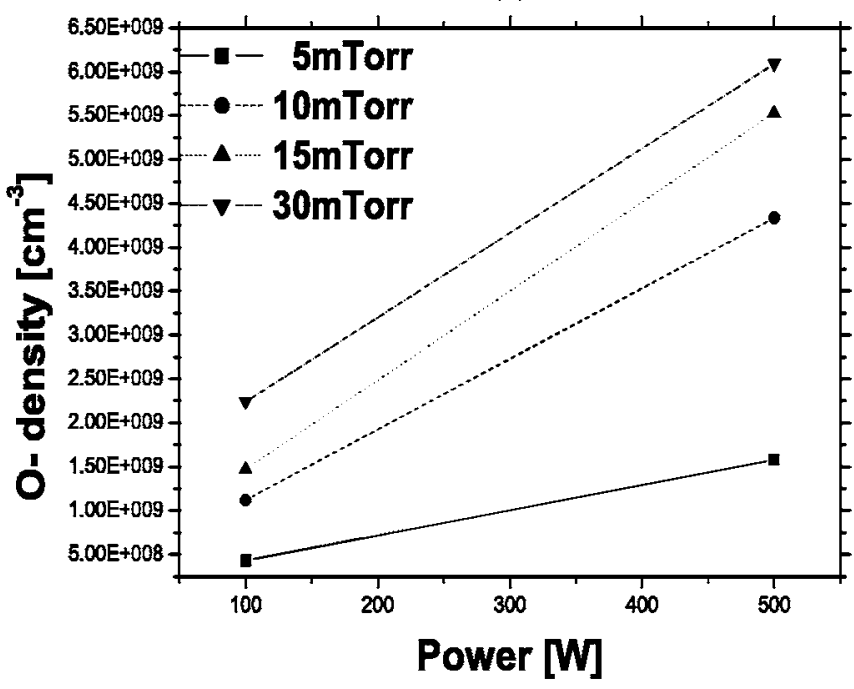

(b)

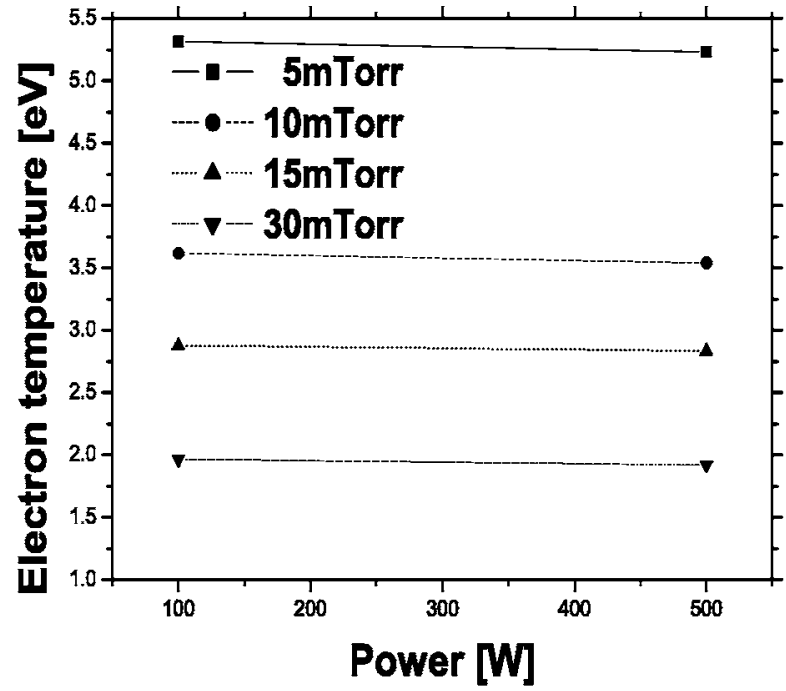

(c)

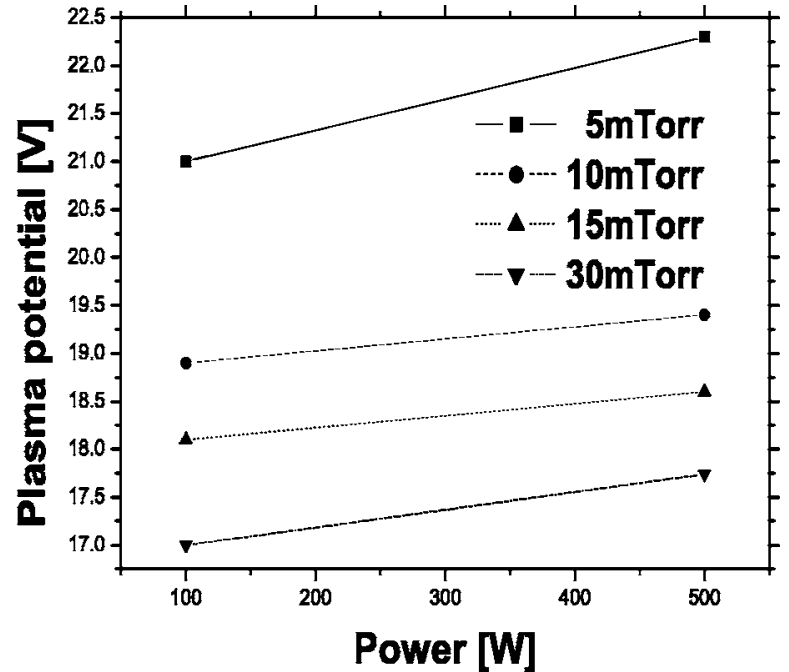

(d)

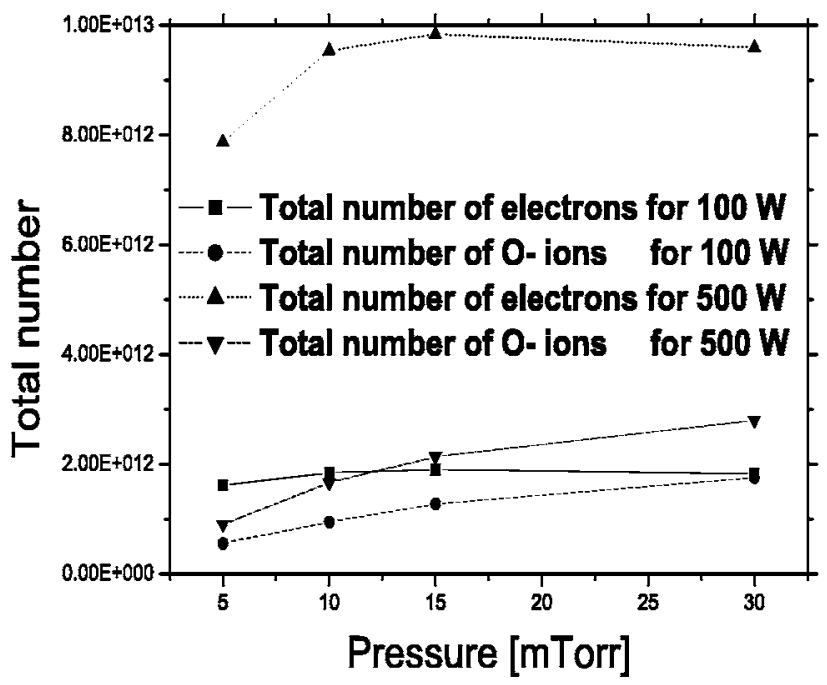

(e)

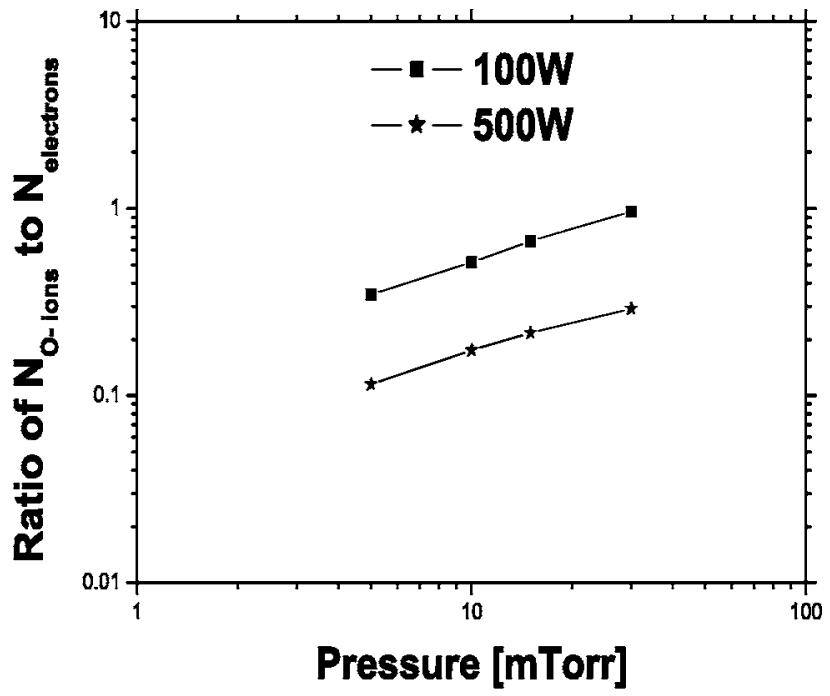

(f)

FIG. 10. Plasma profiles obtained by 2D fluid simulation of a pure oxygen plasma with input power and pressure. (a) Electron density obtained at a radius of $1 \mathrm{~cm}$ and length of $2.5 \mathrm{~cm}$; (b) $\mathrm{O}^{-}$density obtained at a radius of $1 \mathrm{~cm}$ and length of $2.5 \mathrm{~cm}$; (c) electron temperature; (d) plasma potential; (e) total number of electrons and $\mathrm{O}^{-}$ions with pressure and power; (f) ratio of the total number of $\mathrm{O}^{-}$ions to the total number of electrons with pressure and power. 
the electron and negative ion density, the electron temperature, the plasma potential, and the ratio of the total number of negative ions to the total number of electrons as a function of pressure and power. The electron and negative ion densities calculated by the 2D fluid simulation are observed at radius $R=1 \mathrm{~cm}$ and length $L=2.5 \mathrm{~cm}$.

Figure 10(a) shows that the electron density increases linearly with increasing input power. Initially it also increases with pressure but for pressures above $10 \mathrm{mTorr}$ it decreases. The electron densities calculated by the $2 \mathrm{D}$ fluid simulation are $2.08 \times 10^{11}$ and $1.09 \times 10^{11} \mathrm{~cm}^{-3}$ for 100 and $500 \mathrm{~W}$ at a pressure of $5 \mathrm{mTorr}$, respectively. The electron density with respect to input power agrees well with the experimental data measured by Kiehlbauch et al. ${ }^{15}$ The electron densities calculated by the 2D fluid simulation are 1.05 $\times 10^{11} \mathrm{~cm}^{-3}, 1.09 \times 10^{11} \mathrm{~cm}^{-3}, 9.42 \times 10^{10} \mathrm{~cm}^{-3}$, and 8.76 $\times 10^{10} \mathrm{~cm}^{-3}$ for $5,10,15$, and $30 \mathrm{mTorr}$ at an input power of $500 \mathrm{~W}$, respectively. The trend of electron density with respect to a pressure agrees well with the simulation result calculated by $\mathrm{Xu}$ et al. ${ }^{18}$ As the pressure increases, electron temperature and plasma potential decreases. The ratio of total number of negative ions to total number of electrons increases with increasing pressure but decreases with increasing power. These results, as shown in Fig. 10(f), are similar to those calculated using the global model. ${ }^{17}$

\section{CONCLUSIONS}

One-dimensional particle-in-cell/Monte Carlo-collision and two-dimensional fluid modeling of argon-oxygen plasma sources were investigated in a wide parameter range. As the pressure increases, the density of $\mathrm{O}^{-}$and $\mathrm{O}_{2}^{+}$in the bulk decreases due to mutual recombination. As the $\mathrm{Ar} / \mathrm{O}_{2}$ ratio increases, the plasma density increases and the dominant collision affecting the IEDF of $\mathrm{O}_{2}^{+}$changes from CX to MT. The PIC-MCC simulation data were shown to agree well with experimental data in CCPs and can include various electron and ion kinetic information (electron and ion energy distributions and temperatures), which is important for understanding the plasma phenomena. On the other hand, the fluid simulation of CCPs cannot describe the electron and ion kinetic motion, and it is limited to high pressure discharges due to inherent approximations.

\section{ACKNOWLEDGMENTS}

The authors thank Dr. N. Yu. Babaeva and Dr. O. Manuilenko for implementing argon-oxygen Monte Carlo collisions in the oxygen XPDC1 code.

This work was supported in part by the Tera-level Nano Devices Project No. 21c Frontier R\&D Program in the Korea Ministry of Science and Technology.

${ }^{1}$ D. A. Carl, D. W. Hess, and M. A. Lieberman, J. Vac. Sci. Technol. A 8, 2924 (1990).

${ }^{2}$ M. Kitajima, H. Kuroki, H. Shinno, and K. G. Nakamura, Solid State Commun. 83, 385 (1992)

${ }^{3}$ M. A. Lieberman and A. J. Lichtenberg, Principles of Plasma Discharges and Materials Processing, 2nd ed. (Wiley, New York, 2005).

${ }^{4}$ H. C. Kim, F. Iza, S. S. Yang, M. Radmilovic-Radjenovic, and J. K. Lee, J. Phys. D 38, 283 (2005).

${ }^{5}$ P. L. G. Ventzek, R. J. Hoekstra, and M. J. Kushner, J. Vac. Sci. Technol. B 12, 461 (1994).

${ }^{6}$ S. Deshmukh and D. J. Economou, J. Vac. Sci. Technol. B 11, 206 (1993).

${ }^{7}$ K. Kondo, H. Kuroda, and T. Makabe, Appl. Phys. Lett. 65, 31 (1994).

${ }^{8}$ C. K. Birdsall, IEEE Trans. Plasma Sci. 19, 65 (1991).

${ }^{9}$ M. M. Turner and H. B. Hopkins, Phys. Rev. Lett. 69, 3511 (1992).

${ }^{10}$ H. C. Kim and J. K. Lee, Phys. Rev. Lett. 93, 085003 (2004).

${ }^{11}$ V. A. Godyak and R. B. Piejak, Phys. Rev. Lett. 65, 996 (1990).

${ }^{12}$ H. C. Kim, O. Manuilenko, and J. K. Lee, Jpn. J. Appl. Phys., Part 144, 1957 (2005).

${ }^{13}$ S. V. Berezhnoj, C. B. Shin, U. Buddemeier, and I. Kaganovich, Appl. Phys. Lett. 77, 800 (2000).

${ }^{14}$ H. M. Katsch, T. Sturm, E. Quandt, and H. F. Döbele, Physiol. Rev. 9, 323 (2000).

${ }^{15}$ M. W. Kiehlbauch and D. B. Graves, J. Vac. Sci. Technol. A 21, 660 (2003).

${ }^{16}$ N. Yu. Babaeva, J. K. Lee, J. W. Shon, and E. A. Hudson, J. Vac. Sci. Technol. A 23, 699 (2005).

${ }^{17}$ J. T. Gudmundsson, I. G. Kouznetsov, K. K. Patel, and M. A. Lieberman, J. Phys. D 34, 1100 (2001).

${ }^{18}$ X. P. Xu, S. Rauf, and M. J. Kushner, J. Vac. Sci. Technol. A 18, 213 (2000).

${ }^{19}$ E. A. Bogdanov, A. A. Kudryavtsev, L. D. Tsendin, R. R. Arslanbekov, V. I. Kolobov, and V. V. Kudryavtsev, Tech. Phys. 48, 983 (2003).

${ }^{20}$ K. Takechi and M. A. Lieberman, J. Appl. Phys. 90, 3205 (2001)

${ }^{21}$ E. Kawamura, V. Vahedi, M. A. Lieberman, and C. K. Birdsall, Plasma Sources Sci. Technol. 8, R45 (1999).

${ }^{22}$ M. Shibata, N. Nakano, and T. Makabe, J. Appl. Phys. 80, 6142 (1996).

${ }^{23}$ M. Shibata, N. Nakano, and T. Makabe, J. Appl. Phys. 77, 6181 (1995). 